\title{
Leader Readiness in a Volatile, Uncertain, Complex, and Ambiguous Business Environment
}

\author{
Karen Rimita, $\mathrm{PhD}$ \\ Walden University, Minneapolis, Minnesota, United States \\ Stephanie N. Hoon, PhD \\ Walden University, Minneapolis, Minnesota, United States \\ Robert Levasseur, $\mathrm{PhD}$ \\ Walden University, Minneapolis, Minnesota, United States \\ (iD https://orcid.org/0000-0002-2217-5042
}

Contact: karen.rimita@waldenu.edu

\begin{abstract}
Organizational leaders in the 21st century face relentless changes in the business environments in which they operate. The diversity, intensity, and rapidity of these changes create volatility, uncertainty, complexity, and ambiguity (VUCA), which challenge leaders on ways to lead effectively as existing methods prove inadequate. The problem in this study was that of inadequate leader preparedness to lead and win in VUCA environments. The purpose of this hermeneutic phenomenological study was to explore the lived experiences of 15 Nigerian corporate executives about their VUCA business environment and the strategies they employed for VUCAreadiness and success using open-ended interview questions. The conceptual framework guiding this study was a combination of chaos theory and complexity leadership theory. Through Ricoeur's theory of interpretation, member checking, and contextual triangulation, 11 key themes emerged to highlight key coping and readiness strategies for leaders operating in turbulent environments. The key recommendations for practice are to inculcate VUCA-readiness and organizational resilience principles in line with this study's findings. The study findings may contribute to positive social change in providing strategies for organizational sustainability, firm success, business readiness, responsive leadership, and enhanced employee well-being.
\end{abstract}

Keywords: leadership; VUCA; readiness; change; volatility; uncertainty; complexity; ambiguity; complexity leadership; turbulent business environments

Date Submitted: November 12, 2019 | Date Published: January 30, 2020

\section{Recommended Citation}

Rimita, K., Hoon, S. N., \& Levasseur, R. (2020). Leader readiness in a volatile, uncertain, complex, and ambiguous business environment. Journal of Social Change, 12, 10-18. https://doi.org/10.5590/JOSC.2020.12.1.02 


\section{Introduction}

Organizational leaders in the 21st century face dynamic and profound change that is unprecedented with the speed, intensity, and frequency of change ascending rapidly to produce operating environments with volatility, uncertainty, complexity, and ambiguity (VUCA; Bereznoy, 2017; Johansen \& Euchner, 2013; Matthysen \& Harris, 2018). VUCA refers to an operating environment that is constantly changing in conflicting, dramatic, and relentless ways to produce leadership and organizational challenges (Deaton, 2018). Deaton observed that the current turbulence confounded leaders due to its novelty and because proven approaches were inadequate in the VUCA world. A recent study of 13,124 leaders indicated that VUCA was the greatest challenge facing leaders in this century and, unfortunately, the research exposed that only $18 \%$ of leaders were capable of leading in a VUCA world (Development Dimension International, 2015). The requirement for readiness as a leader competency would help leaders facing high pressure, frequent changes, and ambiguous and uncertain environments to balance the conflicting and opposing issues in a mature and calm way to thrive in the unknown (Kayes, 2018). The challenge identified in this study was that few leaders are VUCA ready, meaning that they are ill-prepared to deal with VUCA challenges and, as such, use traditional leadership tools that are linear in a nonlinear and highly disruptive business environment. A deeper understanding of VUCA is likely to increase leader readiness in times of confounding change.

\section{Background}

The focus of this study was on VUCA readiness as a key leadership construct that is indispensable in a new world order characterized by unparalleled change and confusion. The context of leadership in a VUCA world and the complexity surrounding decision-making in times of VUCA prove problematic. VUCA challenges the very essence of Henri Fayol's thinking and the cornerstone of management where planning, controling, organizing, commanding, and coordinating are no longer possible in a highly turbulent business environment. Profound change disrupts leadership and organizational models designed for reliability and accountability, which in a VUCA world creates inertia and resistance to transformation (Hannan \& Freeman, 1984).

VUCA readiness encompasses leadership intelligence and sensemaking to conceptualize competing narratives to sense and respond astutely to VUCA challenges (Burt et al., 2017; Salicru, 2018). Understanding VUCA from a leader readiness perspective may equip organizational leaders with technical, structural, and psychological tools to manage the onslaught of change facing firms in the 21st century. Horney and O'Shea (2015) discussed the importance of VUCA readiness for organizational leaders as it prepares them to anticipate and respond to change in a multipolar world. Lack of VUCA readiness may cause corporate executives to suffer from increased stress and other mental health issues, and organizations to perform poorly due to the unpredictability, chaos, complexity, and confusion present in the operating environment (Abdelzaher et al., 2017; Millar et al., 2018). Increased understanding of VUCA and how corporate executives can enhance their VUCA readiness could add new knowledge to both theory and practice, which, in turn, may help avert VUCA-related problems (Bennett \& Lemoine, 2014; Horney \& O’Shea, 2015).

\section{Method}

The purpose of this hermeneutic phenomenological study was to explore the lived experiences of Nigerian corporate executives about their VUCA business environment and the strategies they employed for VUCA readiness within the manufacturing industry. The population for this study included 15 senior executive leaders in manufacturing organizations that had at least 5 years of experience in key leadership positions. Using both purposive and snowball sampling criteria ensured the selection of leaders with strategic decision- 
making powers to capture a broad and holistic overview of important strategies for leading in turbulent business environments. A deliberate inquiry process helped to ascertain the selection of information-rich participants who were unique from each other and provided a wide range of experience necessary to enrich the research findings (van Manen, 1997).

The interview protocol used for data collection was a researcher-developed instrument containing seven openended questions all reflective of the overarching research question. The in-depth data-collection process involved individual participants in separate sessions that took approximately $1 \mathrm{hr}$ each. The first author used Microsoft Word and Excel data to transcribe and hand code the collected data. For data analysis and theming, the first author used Ricoeur's theory of interpretation a tool for data analysis in hermeneutic phenomenology to ensure rigor and conformance to the research design (Ricoeur, 1981; Tan et al., 2009).

\section{Results}

Using verbatim data transcribed from the 15 interviews and the back and forth data interpretation process of the hermeneutic arc, 11 final themes emerged. Only themes supported by at least 12 participants made the final list. Table 1 displays the 11 final themes and the total supporting participants for each. These 11 themes represent key strategies executives used for coping in a VUCA environment and for VUCA readiness.

Table 1. Final Themes With Supporting Participants

\begin{tabular}{lc}
\hline \multicolumn{1}{c}{ Theme } & Total supporting participants $(N=\mathbf{1 5})$ \\
\hline Business agility & 15 \\
Strategic workforce and demand planning & 15 \\
System thinking organization and shared leadership & 15 \\
Multistakeholder-approach management & 15 \\
Purpose-driven leadership & 15 \\
Conscientious and value-based leadership & 14 \\
Talent management sustainability & 14 \\
Recovery management for organizational resilience & 13 \\
New leadership mindset and competence & 13 \\
Change orientation and readiness & 12 \\
Lean management & 12 \\
\hline
\end{tabular}

For purposes of brevity, the following discussion covers the first five themes only.

\section{Theme 1: Business Agility}

All the participants agreed that business agility was the main strategy they used for VUCA readiness and succeeding in a VUCA environment. They discussed agility in every aspect of dealing with VUCA and how they juggled so many things at any point in time. They talked about having to be nimble, flexible, responsive, agile, and quick. Participant 5 explained that preparing for VUCA was about becoming nimble with decisions, responding quickly as markets changed, becoming dynamic and agile in decision-making. However, speed was the ultimate description of agility in this study; speed to correctly sense, discern, and respond to environmental stimuli was the difference between winning and losing in highly turbulent markets. 


\section{Theme 2: Strategic Workforce and Demand Planning}

Resource planning was an important strategy to win in VUCA environments due to the many changes that affected the normal operations of a company. Adjusting plans and redirecting efforts toward the most crucial area or issue paid dividends and cushioned the organization from serious repercussions. Participant 6 stated, "Prepare and plan your demand and supply for the worst-case scenario; also, adapt to the situation by having modular people that can respond to the changing market."

The results strongly suggested that to succeed organizations operating in a VUCA environment had to align their human resources with a fluid business strategy and to re-engineer processes for flexibility. This ensured efficient responses to fluctuating customer demands and enabled quick adaptation to changing environmental dynamics.

\section{Theme 3: System Thinking Organization and Shared Leadership}

Holistic system interaction and employee engagement brought synergy and fresh thinking to read the markets effectively, analyze environmental changes, and innovatively design system solutions. Participants noted that leaders had to move away from linearity and closed loop thinking and needed to adopt a consulting style of working. Participant 3 stated,

I think the concept of system thinking means moving away from linearity and adopting ways of looking at things from holistic interrelationships, interdependencies, as well as analyzing end-to-end impacts. This requires people who are able to lead the way in the new ways of working.

Empowerment allowed shared leadership and faster decision-making to take advantage of opportunities emerging in the chaos. Trusting the employees to make the right decisions meant sharing the vision, as rigid and complacent thought processes in the face of VUCA blinded leadership.

\section{Theme 4: Multistakeholder-Approach Management}

The participants observed that a major strategic advantage in VUCA was the ability to deal with multiple stakeholders to create networks for collaboration and partnership. They observed that networking created multiple points of information while partnerships created backups for fragile working streams. Participant 7 mentioned the need to have synergy with multiple stakeholders to understand the environment and create critical relationships that helped to bounce back from shocks. Participant 10 described the need to manage stakeholders consistently to gather information, understand context, and get accurate data for planning. Stakeholder management in VUCA goes beyond relationships toward the creation of multiple points of resilience (Participant 3) and access to multiple forms of approaches to unique problems (Participant 1).

\section{Theme 5: Purpose-Driven Leadership}

Purpose-driven leadership emerged as the most vital leadership style in chaos and complexity as it provided organizational and employee direction and a steadfast vision. Leaders stated that purpose-driven leadership included leveraging employees' reasons for existence and their purpose to be able to drive the organization. They also noted that purpose-driven leadership helped in sustainability efforts as the organizational purpose guided decision-making and behavior toward mindfulness.

Participant 15 stated that a strong and well-crafted organizational purpose lived through the volatility, offered comfort during difficult times, and provided stability. The challenge for leaders was to drive this purpose consistently. 
Rimita et al., 2020

\section{Discussion}

The findings from this study comprise 11 strategies leaders use to cope and win in highly VUCA environments. These strategies are consistent with the extant literature and do not contradict either previous research or the conceptual literature on VUCA. The coping and readiness strategies of business agility, workforce and demand planning, recovery management principles, change orientation, and new leader competencies are prominent strategies in VUCA literature and in management journals. However, studies on VUCA are still in their infancy as VUCA is a novel phenomenon in the management and organizational domain, although it forms a topical management challenge for leaders in the 21st century (Nandram, 2017). The findings from this study are consistent with those of key authors in the field of VUCA.

The most discussed finding in both literature and in this study was the need for agility as a winning formula for organizations operating in VUCA environments. In the literature, several authors, such as Bennett and Lemoine (2014), Horney et al. (2010), Horney and O'Shea (2015), and Sopelana et al. (2014), identified business agility as the single most critical strategy for organizational success in a VUCA environment. These authors observed that agility in VUCA referred to creating alignment between people, process, and technology to enhance the speed of response to VUCA-associated elements through focus and flexibility in organizational structures. All of the participants in this study identified this as a key strategy for achieving success in a VUCA environment.

The participants added that in VUCA environments, it was critical to work with a network to achieve smart targets due to the multiplicity of issues. The participants identified the strategies of systems thinking, multistakeholder management, and talent management sustainability as necessary ingredients for success in VUCA. On systems thinking, Aufegger and colleagues (2019) evaluated systems thinking as a tool for resolving complex problems in organizations through deliberate coordination, interventions, and creative effort. On multistakeholder-approach management, Orazi and colleagues (2017) suggested that as organizations planned toward uncertainties, they required a strategic focus within a complex system of multiple stakeholders in collaborative and equitable partnerships for achieving more sustainable performance. Mwila and Turay (2018) explained that talent management in VUCA was a process that transformed employees into a fluid strategy, which aptly coincides with the participants' assertions on the need for swifter sensing and responses toward change.

Because this was a leadership study, it was necessary to ask how leadership benefited an organization in times of crisis. The participants discussed the need to apply several leadership styles-such as shared, conscientious and value based, and purpose driven-to enhance flexibility in decision-making, harness the power of the network, and inject ethics into every decision. Shared leadership allowed members of the team to engage in the decision-making process by influencing and mutual guidance in a continuous shift of the team position from leader to follower and vice versa for faster and better decisions in unpredictable and complex times (Best et al., 2016). Conscientious and value-based leadership is indicative of the many ethical dilemmas present in a VUCA environment and alludes to what the participants' identified as a key need for ethical leadership, also discussed by Lajoie et al. (2017). The participants noted that in VUCA environments, purpose-driven leaders focused on helping others cope with elusive and volatile forces while maintaining a vision and hope that transcended the current reality. Coccia (2015) stated that purpose-driven leadership was a model that aligned aspects of running organizations with the core values and beliefs of the said organization as a way to remain sustainable irrespective of the turbulent nature of the environment. These findings confirm that leadership remains the foundational organizational strength in both VUCA and non-VUCA times.

The findings may contribute to filling some of the identified gaps in the literature review by (a) providing a Sub-Saharan African perspective on VUCA studies that is currently lacking, (b) providing a management 
perspective on VUCA, (c) introducing readiness as a critical competency, and (d) providing a hermeneutic phenomenological research approach to the issues faced in VUCA environments. That said, leaders need to be judicious as they apply the findings from this study to ensure situational appropriateness.

\section{Implications for Social Change}

Leaders in organizations contribute significantly to society and create positive social change in many ways that promote the dignity of their employees and the communities in which they operate. The VUCA problems identified in this study include high closure rates of manufacturing firms, relocations to other countries, economic and financial losses, and increased retrenchment. These business-related problems converge and translate into social problems due to reduced economic activity and increased unemployment. Understanding how to lead in a VUCA environment may contribute to business success, thereby alleviating negative individual, corporate, and societal problems stemming from failing organizational operations (Saleh \& Watson, 2017; Vecchiato, 2015).

Studies in VUCA promote empirical knowledge generation that better prepares leaders to face persistent change by enhancing organizational leader readiness, awareness, and their understanding of complexity management in an era of constant change (Choain \& Malzy, 2017). The findings of this study may contribute to new knowledge, assist leaders through the emotional turmoil brought on by VUCA, and inform leaders on ways to be VUCA-ready to reduce instances of corporate failures that lead to negative social impact. Johansen and Euchner (2013) opined that readiness helped leaders find clarity of direction and aptly flip dilemmas into opportunities when faced with VUCA. The findings from this study may increase understanding and document these readiness strategies for leaders to refer to and apply in a bid to strengthen the practical knowledge of efficiently managing VUCA and consequently reducing the change failure.

The findings could inform current and future leaders on ways to ensure that their strategies are robust, agile, and sufficiently adaptive to navigate in a highly complex environment. At an organizational level, understanding how to navigate VUCA could build organizational resilience, thereby minimizing the impact of damage and operational losses (Ishak \& Williams, 2018). At an individual level, resilience promotes positive social change through functional and agile teams that can withstand the onslaught of persistent change.

The importance of agility and recovery came out strongly in the leadership feedback for VUCA survival. Both agility and recovery are key skills for organizations and also for individuals and societies in the 21st century, where change is a constant feature. To achieve positive social change in constantly changing circumstances, people, families, organizations, and societies must learn to be agile and to enhance recovery mechanisms. The conceptual framework of chaos theory and complexity leadership theory underscore the need to modify behavior and adapt based on environmental cues.

The implication of multistakeholder-approach management as a key theme in this study strongly epitomizes positive social change. When groups and people come together, they create a support network that enables the greater performance of the social and economic system due to the shared vision and enhanced systems thinking. The collaboration and partnership found in multistakeholder-approaches to work foster relationships necessary for sensemaking in turbulent times.

In institutions of higher learning, the strategies may adequately prepare students in business related courses by teaching them key VUCA strategies and competences, which are necessary survival toolkits for leaders in the 21st century. Hall and Rowland (2016) observed that Masters of Business Administration courses were still stuck in an age before VUCA and noted the need for educational institutions to update their curriculum to include leadership skills for managing in VUCA environments. 
Organizations can use this study's learning to enhance positive social change by applying the emerging themes of shared leadership, conscientious and value-based leadership, multistakeholder-approach management, change readiness, talent management sustainability, and purpose-driven leadership. These themes have the added benefit of empowering employees, injecting ethics into decision-making and leadership, directly growing employees, managing their talent, and preparing them to win despite the odds. The themes touch at the very essence of what it means to be socially responsive.

\section{Recommendations}

Several opportunities exist for future research and for practice. The participants of this study were senior executives, essentially chief executive officers and directors mainly working in multinational corporations, all of whom were male. These demographics alone present many avenues to further this study. For example, for future researchers, using female executives and followers as participants may provide a different perspective from the one presented here. Different points of view allow a broader understanding of the phenomenon and additionally help cement the circle of understanding. Replicating this study to other types of organizations, sectors, and countries may provide confirmatory or contradictory data for an enhanced understanding of VUCA.The testing of the study findings quantitatively may allow for generalization and the formulation of frameworks relevant for leader training and application. For practice, it is important to train leaders on strategies they can use to enhance their VUCA-preparedness and for organizational resilience. The findings of this study could provide an avenue for these trainings and additionally offer guidance for new competency requirements.

\section{Conclusion}

This study contributes to VUCA literature by providing a Sub-Saharan African perspective on VUCA studies that is currently lacking, providing a management perspective on VUCA (Nandram, 2017), introducing readiness as a necessary competence in VUCA and leadership discourse, and providing a hermeneutic phenomenological study on VUCA (Choain \& Malzy, 2017). Closing existing research gaps enhances learning and opens up new avenues for further research to ensure a multiplicity of perspectives for researchers, leaders, and institutional consumption.

The findings support positive social change by providing strategies for leaders to apply in VUCA environments to achieve success thus preventing failure and reducing employee stress levels brought on by constant change and uncertainty. In a world where markets are constantly changing in VUCA ways, leaders require to augment their skills, mindsets, and daily strategies to ensure survival and longevity. Agility, resilience, recovery, stakeholder alliance, leadership, change orientation, lean thinking, and new competences were some of the key findings in this study.

\section{References}

Abdelzaher, D., Latheef, Z., \& Abdelzaher, A. (2017). Recovering from conflict and uncertainty post-Arab spring. International Journal of Conflict Management, 28(2), 222-244. https://doi.org/10.1108/IJCMA-02-2016-0005

Aufegger, L., Shariq, O., Bicknell, C., Ashrafian, H., \& Darzi, A. (2019). Can shared leadership enhance clinical team management? A systematic review. Leadership in Health Services, 32(2), 309-335. https://doi.org/10.1108/lhs-06-2018-0033

Bennett, N., \& Lemoine, G. J. (2014). What a difference a word makes: Understanding threats to performance in a VUCA world. Business Horizons, 57, 311-317. https://doi.org/10.1016/j.bushor.2014.01.001 
Bereznoy, A. (2017). Corporate foresight in multinational business strategies. Foresight and STI Governance, 11(1), 9-22. https://doi.org/10.17323/2500-2597.2017.1.9.22

Best, A., Berland, A., Herbert, C., Bitz, J., van Dijk, M. W., Krause, C., . . Millar, J. (2016). Using systems thinking to support clinical system transformation. Journal of Health Organization and Management, 3O(3), 302-323. https://doi.org/10.1108/jhom-12-2014-0206

Burt, G., Mackay, D. J., van der Heijden, K., \& Verheijdt, C. (2017). Openness disposition: Readiness characteristics that influence participant benefits from scenario planning as strategic conversation. Technological Forecasting and Social Change, 124, 16-25. https://doi.org/10.1016/j.techfore.2016.11.024

Choain, L., \& Malzy, T. (2017). Research by professionals: From a knowledge-intensive to a research-intensive PSF. International Journal of Human Resource Management, 28(2), 276-282. https://doi.org/10.1080/09585192.2016.1244896

Coccia, M. (2015). General sources of general purpose technologies in complex societies: Theory of global leadership-driven innovation, warfare and human development. Technology in Society, 42, 199-226. https://doi.org/10.1016/j.techsoc.2015.05.008

Deaton, A. V. (2018). VUCA tools for a VUCA world: Developing leaders and teams for sustainable results. Da Vinci.

Development Dimension International. (2015). Global leadership forecast 2014/2015. https://www.ddiworld.com/glf2014

Hall, R. D., \& Rowland, C. A. (2016). Leadership development for managers in turbulent times. Journal of Management Development, 35(8), 942-955. https://doi.org/10.1108/JMD-09-2015-0121

Hannan, M. T., \& Freeman, J. (1984). Structural inertia and organizational change. American Sociological Review, 49(2), 149-164. https://doi.org/10.2307/2095567

Horney, N., \& O’Shea, T. (2015). Focused, fast, and flexible: Creating agility advantage in a VUCA world. Indie.

Horney, N., Pasmore, B., \& O'Shea, T. (2010). Leadership agility: A business imperative for a VUCA world. People \& Strategy, 33(4), 32-38.

Ishak, A. W., \& Williams, E. A. (2018). A dynamic model of organizational resilience: Adaptive and anchored approaches. Corporate Communications: An International Journal, 23(2), 180-196. https://doi.org/10.1108/ccij-04-2017-0037

Johansen, B., \& Euchner, J. (2013). Navigating the VUCA World. Research Technology Management, 56(1), 10-15. https://doi.org/10.5437/08956308x5601003

Kayes, D. C. (2018). Are you ready to lead in a crisis? Organizational Dynamics, 48(2), 1-7. https://doi.org/10.1016/j.orgdyn.2018.05.003

Lajoie, D., Boudrias, J., Rousseau, V., \& Brunelle, É. (2017). Value congruence and tenure as moderators of transformational leadership effects. Leadership \& Organization Development Journal, 38(2), 254269. https://doi.org/10.1108/lodj-04-2015-0091

Matthysen, M., \& Harris, C. (2018). The relationship between readiness to change and work engagement: A case study in an accounting firm undergoing change. SA Journal of Human Resource Management, 16, 1-11. https://doi.org/10.4102/sajhrm. v16io.855 
Millar, C. C. J. M., Groth, O., \& Mahon, J. F. (2018). Management innovation in a VUCA world: Challenges and recommendations. California Management Review, 61(1), 5-14. https://doi.org/10.1177/0008125618805111

Mwila, N. K., \& Turay, M. I. S. (2018). Augmenting talent management for sustainable development in Africa. World Journal of Entrepreneurship, Management and Sustainable Development, 14(1), 41-49. https://doi.org/10.1108/wjemsd-03-2017-0012

Nandram, S. (2017). Integrating simplification theory for navigating the VUCA: The case of Buurtzorg Nederland. In P. Bindlish, \& S. Nandram (Eds.), Managing VUCA through integrative selfmanagement (pp. 263-287). Springer. https://doi.org/10.1007/978-3-319-52231-9 18

Orazi, D. C., Spry, A., Theilacker, M. N., \& Vredenburg, J. (2017). A multi-stakeholder IMC framework for networked brand identity. European Journal of Marketing, 51(3), 551-571. https://doi.org/10.1108/ejm-08-2015-0612

Ricoeur, P. (1981). Paul Ricoeur hermeneutics and the human sciences (J. B. Thompson, Ed.). Cambridge.

Saleh, A., \& Watson, R. (2017). Business excellence in a volatile, uncertain, complex and ambiguous environment (BEVUCA). TQM Journal, 29, 705-724. https://doi.org/10.1108/TQM-12-2016-0109

Salicru, S. (2018). Storytelling as a leadership practice for sensemaking to drive change in times of turbulence and high velocity. Journal of Leadership, Accountability, and Ethics, 15(2), 130-140.

Sopelana, A., Kunc, M., \& Hernáez, O. R. (2014). Towards a dynamic model of organizational flexibility. Systemic Practice and Action Research, 27(2), 165-183. https://doi.org/10.1007/s11213012-9274-4

Tan, H., Wilson, A., \& Olver, I. (2009). Ricoeur's theory of interpretation: An instrument for data interpretation in hermeneutic phenomenology. International Journal of Qualitative Methods, 8(4), 1-15. https://doi.org/10.1177/160940690900800401

van Manen, M. (1997). Researching lived experience: Human science for an action sensitive pedagogy (2nd ed.). The Althouse Press.

Vecchiato, R. (2015). Strategic planning and organizational flexibility in turbulent environments. Foresight: The Journal of Futures Studies, Strategic Thinking, and Policy, 17, 257-273. https://doi.org/10.1108/FS-05-2014-0032 manuscripts focusing on interdisciplinary research in social change that improves the human condition and moves people, groups, organizations, cultures, and society toward a more positive future. 